\title{
Interior Noise Characteristics in Japanese, Korean and Chinese Subways
}

\author{
Yoshiharu Soeta ${ }^{\dagger}$, Ryota Shimokura*, Jin Yong Jeon** and Pyoung Jik Lee***
}

\begin{abstract}
The aim of this study was to clarify the characteristics of interior noise in Japanese, Korean, and Chinese subways. The octave-band noise levels, A-weighted equivalent continuous sound pressure level $\left(\mathrm{L}_{\mathrm{Aeq}}\right)$ and parameters extracted from interaural cross-correlation/autocorrelation functions (ACF/IACFs) were analyzed to evaluate the noise inside running train cars quantitatively and qualitatively. The average $\mathrm{L}_{\mathrm{Aeq}}$ was $72-83 \mathrm{dBA}$. The IACF/ACF parameters of the noise showed variations in their values, suggesting they are affected by the characteristics of the trains running, wheel-rail interaction, and cross-section of the tunnels.
\end{abstract}

Keywords : Train noise in a car, Interaural cross-correlation function, Autocorrelation function, Pitch

\section{Introduction}

The sound quality in train cars is an important design factor for the railway industry because many people occupy trains for long periods of time in large cities. The fundamental issue is to create a comfortable acoustic environment for the passenger in a train car. The rail industry has succeeded in lowering the equivalent sound-pressure level (SPL) in surface train cars to a mean of less than 70 dBA (Hardy 2000; Soeta and Shimokura 2011; 2012; 2013). However, the SPL is higher in underground train cars and lowering it is not enough for a comfortable acoustical environment. Even when the SPL is only about 35 dBA, people may feel irritated by conditions such as fluctuations of pitch and localized sound sources (Kitamura et al. 2002). It was found that the perceived annoyance in train cars could be predicted not only by the SPL but also

\footnotetext{
Corresponding author: Health Research Institute, National Institute of Advanced Industrial Science and Technology (AIST), Japan

E-mail : y.soeta@aist.go.jp

* Department of Otorhinolaryngology-Head and Neck Surgery, Nara Medical University, Japan

** Department of Architectural Engineering, Hanyang University, Korea

**** EMPA, Swiss Federal Laboratories for Materials Science and Technology, 8600, Dübendorf, Switzerland, Acoustics Research Unit, School of Architecture, University of Liverpool, UK

(C) The Korean Society for Railway 2013 http://dx.doi.org/10.7782/IJR.2013.6.3.120
}

parameters extracted from the interaural cross-correlation function (IACF) and autocorrelation function (ACF) (Soeta and Shimokura 2012).

The ACF and IACF parameters were introduced for the evaluations of noise in train cars in Japan (Soeta and Shimokura 2011; 2012; 2013). The results indicated that the effect of the reflection from the tunnel is characterized by a maximum peak for the IACF and the characteristics of the noise sources are described by the delay time, peak amplitude, and width of the peak of the ACF. However, the results relied on a limited budget. To apply the parameters worldwide, more cases for different lines and countries should be analyzed, compared, and discussed.

The aim of this study is to clarify the noise characteristics inside running train cars in the large cities of Eastern Asia using ACF and IACF analysis. To consider an appropriate acoustic treatment, it is necessary to clarify the characteristics of the noise inside train cars quantitatively and qualitatively.

\section{Measurement and Analysis}

We continually measured noise in a subway car traveling between terminal stations on 14 lines. Table 1 lists the number of intervals, number of curves, and average speed for the measured lines. Measurements were carried out in Kyoto, Osaka, and Fukuoka in Japan, Seoul in Korea, and Shanghai in China. Noise inside cars at normal speed and 
Yoshiharu Soeta, Ryota Shimokura, Jin Yong Jeon and Pyoung Jik Lee / IJR, 6(3), 120-124, 2013

Table I Measured subway lines in Japan, Korea, and China (* and ** indicates express and surface line respectively).

\begin{tabular}{ccccccccc}
\hline \hline \multirow{5}{*}{ Japan } & Measured lines & $\begin{array}{c}\text { Number of } \\
\text { intervals }\end{array}$ & $\begin{array}{c}\text { Number of } \\
\text { curves }\end{array}$ & $\begin{array}{c}\text { Average speed } \\
{[\mathrm{km} / \mathrm{h}]}\end{array}$ & $\mathrm{L}_{\max }$ & $\mathrm{L}_{10}$ & $\mathrm{~L}_{50}$ & $\mathrm{~L}_{90}$ \\
\hline \multirow{6}{*}{ Korea } & Kyoto, Line A & 8 & 7 & 41 & 81.3 & 74.6 & 68.8 & 64.1 \\
& Osaka, Line B & 10 & 12 & 38 & 91.8 & 87.5 & 81.4 & 67.9 \\
& Osaka, Line C & 8 & 9 & 37 & 94.3 & 84.1 & 77.1 & 67.3 \\
& Fukuoka, Line D & 12 & 13 & 39 & 87.7 & 78.8 & 72.3 & 60.8 \\
& Fukuoka, Line E & 15 & 11 & 35 & 87.9 & 78.3 & 72.0 & 61.1 \\
\hline \multirow{5}{*}{ China } & Seoul, Line A & 20 & 13 & 30 & 95.9 & 79.7 & 70.9 & 64.4 \\
& Seoul, Line B & 26 & 20 & 40 & 84.2 & 76.5 & 70.5 & 65.9 \\
& Seoul, Line C & 24 & 7 & 35 & 98.6 & 79.0 & 70.4 & 63.5 \\
& Seoul, Line D & 20 & 15 & 35 & 83.9 & 75.8 & 70.0 & 64.0 \\
& Seoul, Line D* & 7 & 15 & 49 & 83.4 & 76.8 & 73.0 & 62.6 \\
\hline & Shanghai, Line A & 9 & 8 & 39 & 89.9 & 79.8 & 71.0 & 64.7 \\
& Shanghai, Line B & 16 & 30 & 42 & 97.7 & 83.1 & 75.5 & 69.1 \\
& Shanghai, Line C** & 8 & 7 & 40 & 88.3 & 76.8 & 71.6 & 66.5 \\
& Shanghai, Line D & 11 & 13 & 42 & 90.3 & 78.6 & 73.7 & 68.7 \\
& Shanghai, Line E & 6 & 10 & 36 & 96.4 & 83.9 & 77.4 & 67.6 \\
\hline
\end{tabular}

limited express trains was measured for a line in Seoul. Cars run on elevated railway tracks most of the time in a line of Shanghai.

We used a dummy-head microphone (KU100, Nuemann) or a binaural microphone (Type 4101; B\&K) to record noise inside a train car. The dummy head is an artificial model of the human head with two microphones inserted at the entrances of the outer ears. It can simulate the frequency-dependent distortions of the phase and amplitude of sound reaching the entrance of the left and right ear canals. The microphone was placed in the area for a wheelchair user because of safety. The dummy or real head always faced the inside of the train car and was perpendicular to the direction of travel. The height of the dummy head and binaural microphones was $1.6 \mathrm{~m}$. For all measurements, noise was recorded on a personal computer or digital audio recorder at a sampling rate of $48 \mathrm{kHz}$ and sampling resolution of 24 bits.

The IACF/ACF parameters of the noise are proposed for describing the sound quality (Ando 2001). The normalized IACF for the signals received at each ear from the microphones, $p_{l}(t)$ and $p_{r}(t)$, as a function of the running step, $s$, is defined by

$$
\phi_{l r}(\tau, s, T)=\frac{\Phi_{l r}(\tau, s, T)}{\sqrt{\Phi_{l l}(0 ; s, T) \Phi_{r r}(0 ; s+\tau, T)}}
$$

where

$$
\Phi_{l r}(\tau, s, T)=\frac{1}{2 T} \int_{s-T}^{s+T} P_{l}^{\prime}(t) P_{r}^{\prime}(t+\tau) d t
$$

Here $\mathrm{F}_{l l}(0)$ and $\mathrm{F}_{r r}(0)$ are the ACFs at $t=0$ for the left and right ears, $2 T$ is the integration interval, and $p^{\prime}{ }_{l, r}(\mathrm{t})=$ $p_{l, r}(t)^{*} s_{e}(t), s_{e}(t)$ is the ear sensitivity. For convenience, we chose $s_{e}(t)$ as the impulse response of an A-weighted network, which includes the transfer function of the human outer and middle ear (Ando 2001; Ando and Cariani 2009). The ACF is normalized by the geometric mean of the energy at $s$ and at $s+\tau$, and should not be normalized by the energy only at $s$. This ensures that the normalized ACF satisfies $\phi_{l r}(0)=1$ and $\phi_{l r}(\tau) \leq 1$ at $\tau>0$.

The octave-band noise levels and the A-weighted equivalent continuous SPL $\left(\mathrm{L}_{\text {Aeq }}\right)$ were determined from the octave-band filtered and A-weighted $p_{l}(t)$ and $p_{r}(t)$ as a function of the running step, $s$. The $\mathrm{L}_{\text {Aeq }}$ is calculated by

$$
L_{A e q}(s, T)=10 \log \sqrt{\Phi_{l l}(s, T) \Phi_{r r}(s, T)},
$$

where $\Phi_{l l}$ and $\Phi_{r r}$ have $\tau=0$. The $\mathrm{L}_{\text {Aeq }}$ was calibrated by the sound calibrator (Type 4231; B\&K). The interaural cross-correlation coefficient (IACC) is related to the subjective diffuseness and apparent source width (ASW) (Ando and Kurihara 1986; Sato and Ando 2002), and is defined by

$$
\operatorname{IACC}(s, T)=\left|\phi_{l r}(\tau, s, T)\right|_{\max },|\tau| \leq 1[\mathrm{~ms}]
$$

When IACC is 1 , the passengers can clearly perceive the direction of the noise source. When IACC approaches 0 , passengers can hear the noise, but it is diffused (Ando 2001).

The normalized ACF can be obtained by substituting $p^{\prime}{ }_{l}(t)\left(p^{\prime}{ }_{r}(t)\right)$ for $p^{\prime}{ }_{r}(t)\left(p^{\prime}{ }_{l}(t)\right)$ in Eqs. (1) and (2). The ACF parameters, $\tau_{1}$ and $\phi_{1}$, are defined as the time delay and amplitude of the first maximum peak and are related to the perceived pitch and pitch strength (i.e., tonality) of the complex sounds (Ando 2001; Yost 1996). The other ACF parameter, $\mathrm{W}_{\Phi(0)}$, is defined as the width of the first decay and corresponds to the spectral centroid (Ando and Cari- 

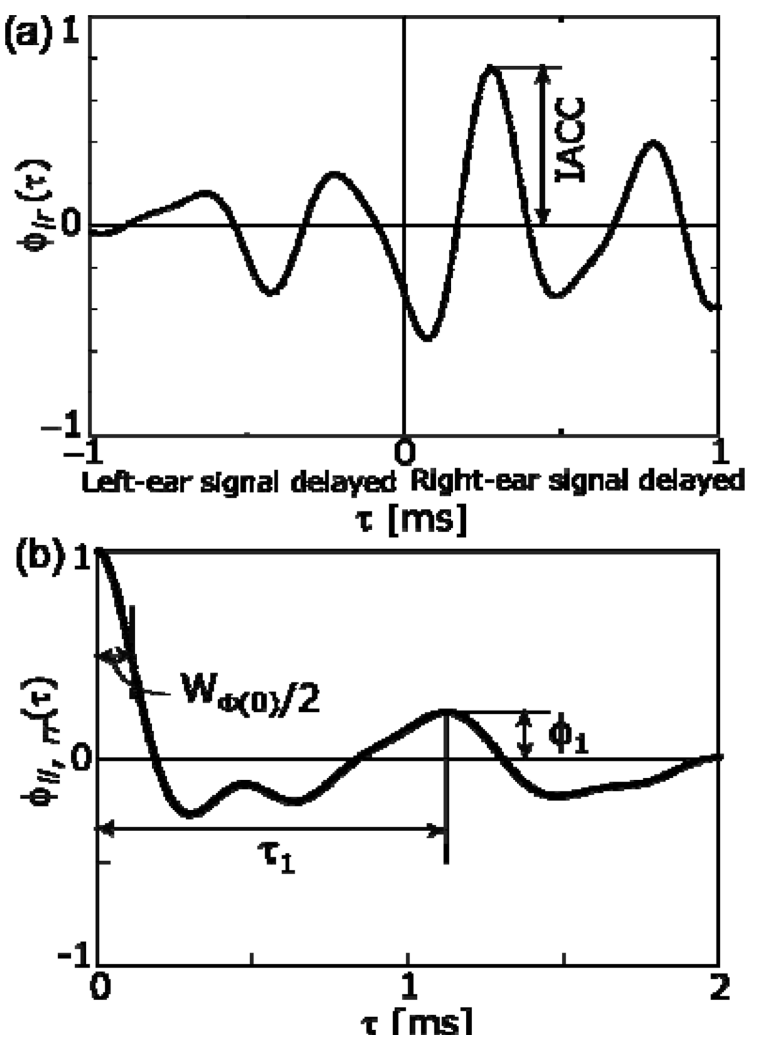

Fig. 1 Definitions of (a) IACC and (b) $\tau_{1}, \phi_{1}$, and $\mathrm{W}_{\Phi(0)}$.

ani 2009). The definitions of IACF and ACF factors are shown in Fig. 1.

We calculated the octave-band noise levels, $\mathrm{L}_{\text {Aeq }}$, IACC, $\tau_{1}, \phi_{1}$, and $\mathrm{W}_{\Phi(0)}$ as a function of time to evaluate the noises in a train car quantitatively and qualitatively. The integration interval was $2 T=0.5 \mathrm{~s}$ and the running step was $s=0.1 \mathrm{~s}$ in all calculations. Although the different head-related transfer functions of the dummy head and binaural microphones can affect the IACF and ACF parameters, the preliminary measurements verified that the difference between the microphones was not significant (Shimokura and Soeta 2011).

\section{Results and Discussion}

Fig. 2 shows the averaged flat, A-weighted, and octave band levels for noises in a running subway. The average $\mathrm{L}_{\text {Aeq }}$ for a Japanese subway varied from 71.8 to $83.2 \mathrm{dBA}$, while the levels for Korean and Chinese subways ranged from 72.0 to $79.1 \mathrm{dBA}$ and 73.1 to $79.9 \mathrm{dBA}$, respectively. The frequency characteristics were similar on all lines of the subways. The two lines in Japan had larger SPL at frequencies between 250 and $4000 \mathrm{~Hz}$. Because they are of the linear motor rapid transit type that has

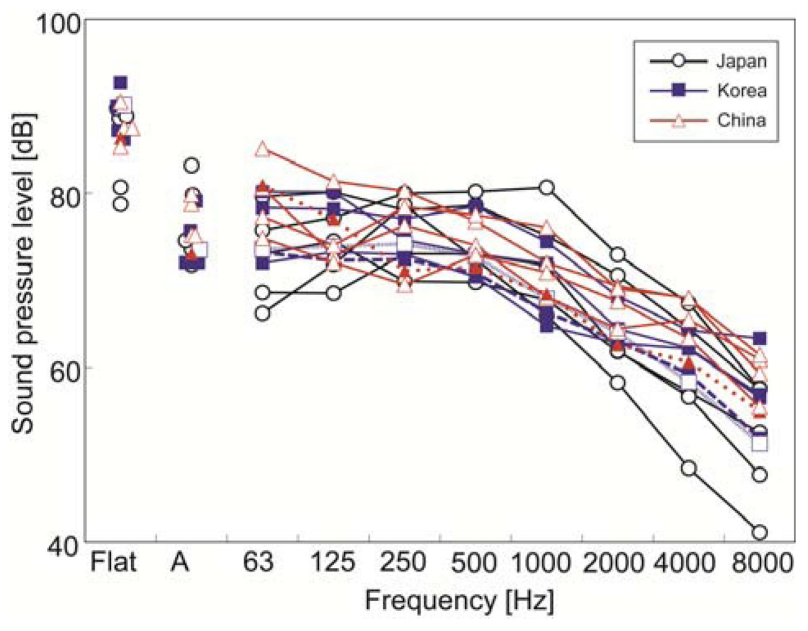

Fig. 2 Measured sound pressure level as a function of the 1/1 octave band center frequency, flat, and $\mathrm{L}_{\text {Aeq }}$ for the Japanese $(\bigcirc)$, Korean $(\boldsymbol{\square})$, and Chinese $(\triangle)$ subways. In the Korean subway, the broken line and empty square compares the normal speed and limited express trains on the same line. In the Chinese subway, filled red triangles show that the cars run on elevated railway tracks most of the time on that line.

smaller cars, the tunnel is smaller and causes many reflections (Soeta and Shimokura 2011; 2012). The quietest line is also of the linear motor rapid transit type, suggesting the effectiveness of the acoustic treatment, such as vibrationproof hard rubber on the railway sleepers. The average $\mathrm{L}_{\mathrm{Aeq}}$ for an express train was approximately $2 \mathrm{~dB}$ higher than that for a normal train on the Seoul line D. Maximum $\left(\mathrm{L}_{\max }\right)$ and statistical noise levels $\left(\mathrm{L}_{10}, \mathrm{~L}_{50}\right.$, and $\left.\mathrm{L}_{90}\right)$ are listed in Table .1.

Fig. 3 (a) shows the frequency distributions of the IACC. Most values are less than 0.4, suggesting the passengers could not hear the direction of noise source clearly. This is consistent with previous findings (Soeta and Shimokura 2011; 2013). There were no significant differences between Japan, Korea, and China, but the frequency distributions show some differences between their respective lines. The IACC is influenced by the cross-section of the tunnels, e.g., the IACC was largest for the tunnel with a circular cross-section because of the focused reflections (Soeta and Shimokura 2011; 2012), suggesting the cross-sections of tunnels are diverse on each line.

Figs. 3 (b) and (c) show the frequency distributions for $\tau_{1}$ and $\phi_{1}$. The $\tau_{1}$ values concentrated around $1.5 \mathrm{~ms}$ in all three countries, which correspond to a frequency of $667 \mathrm{~Hz}$ and caused by the rolling noise (Soeta and Shimokura 2013). The $\tau_{1}$ values also concentrated around $4.0 \mathrm{~ms}$ in Japan, $3.0 \mathrm{~ms}$ in Korea, and $0.5 \mathrm{~ms}$ in China, suggesting the pitch of some noise components inside train 

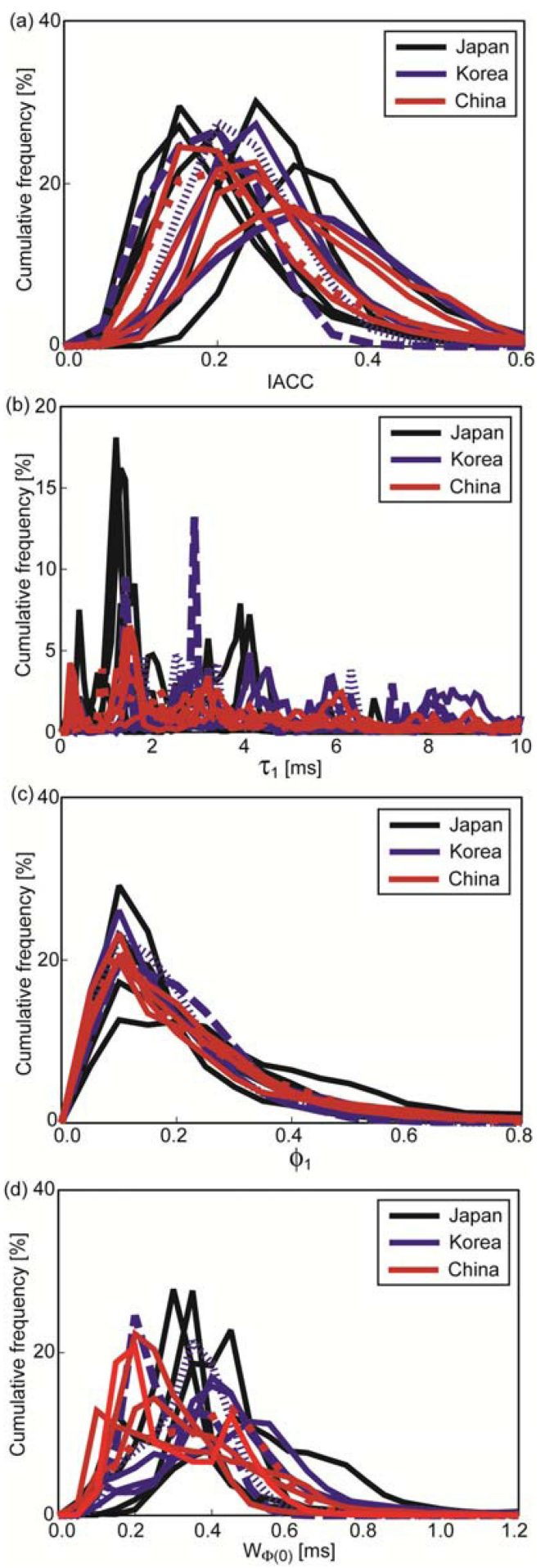

Fig. 3. Frequency distributions of (a) IACC, (b) $t_{1}$, (c) $f_{1}$, and (d) $\mathrm{W}_{\mathrm{F}(0)}$ for the Japanese (-), Korean (-), and Chinese (-) subways. In the Korean subway, long and short dashed lines compare the normal speed and limited express trains on the same line. In the Chinese subway, dotted lines show that the cars run on elevated railway tracks most of the time on that line. cars is different in the three countries. Therefore, noise from Japanese and Korean subways can produce lower perceived pitch than that from Chinese subways. The $\tau_{1}$ values observed in Korea and China were also observed in Japan (Soeta and Shimokura 2013), which show the effects of the types of train and the wheel-rail friction on the $\tau_{1}$ values. Therefore, the difference in $\tau_{1}$ between the three countries reflects the characteristics of the running cars and the wheel-rail interactions in each country. Most $\phi_{1}$ values are less than 0.3 , which is consistent with previous findings (Soeta and Shimokura 2011; 2013). There were no clear differences in $\phi_{1}$ between Japanese, Korean, and Chinese lines, suggesting the pitch strength of noises inside train cars is similar in all three countries.

Fig. 3 (d) shows the frequency distributions of the $W_{\Phi(0)}$. The Chinese subway has lower $\mathrm{W}_{\Phi(0)}$ values compared to Japanese and Korean subways, suggesting the noise inside train cars in a Chinese subway includes more lower frequency components than that in Japanese and Korean subways. This may also reflect the characteristics of running cars (Soeta and Shimokura 2013). Noise in surface cars (Line $\mathrm{C}$ in Shanghai) had a greater $\mathrm{W}_{\Phi(0)}$, disagreeing with the previous results (Soeta and Shimokura 2011; 2012), because the train cars running on the elevated railway tracks cause a low frequency component $(63-1000 \mathrm{~Hz})$ (Kitagawa 2008).

\section{Conclusions}

We analyzed the noise characteristics inside running train cars in Japan, Korea, and China. Noticeable differences of $\mathrm{L}_{\text {Aeq }}$ were not observed between the three countries. ACF factors, $\tau_{1}$ and $\mathrm{W}_{\Phi(0)}$, showed slight differences in the Chinese subway. The variations in the IACF and ACF parameters reflect the characteristics of the trains running, the wheel-rail interaction, and the cross-section of the tunnels, suggesting that these characteristics take into consideration the acoustic treatments in each line of the subway. In the current study, the physical characteristics of noise in train cars were clarified, but the effects on the passengers are not yet resolved. To introduce IACF and ACF parameters for the evaluation and mitigations of noise, further investigations are required to clarify the effects of $\mathrm{ACF}$ and IACF parameters on the passengers.

\section{Acknowledgments}

We thank the railroad staff who cooperated in our measurements. This work was supported by a Grant-in-Aid for Young Scientists (A) from the Japan Society for the Promotion of Science (No. 23686086). 


\section{Reference}

1. Ando, Y., Kurihara, Y. (1986). "Nonlinear Response in Evaluating the Subjective Diffuseness of Sound Field," Journal of the Acoustical Society of America, Vol. 80, pp. 833-836.

2. Ando, Y. (2001). "A Theory of Primary Sensations and Spatial Sensations Measuring Environmental Noise," Journal of Sound and Vibration, Vol. 241, pp. 3-18.

3. Ando, Y., Cariani, P. (2009). "Auditory and Visual Sensations," Springer, New York.

4. Hardy, A. E. (2000). "Measurement and Assessment of Noise Within Passenger Trains," Journal of Sound and Vibration, Vol. 231, pp. 819-829.

5. Kitagawa, T. (2008). "Noise and Vibration Control of Railway Vehicles," Journal of Acoustical Society of Japan, Vol. 64, pp. 629-634. (in Japanese).

6. Kitamura, T., Shimokura, R., Sato, S., Ando, Y. (2002). "Measurement of Temporal and Spatial Factors of a Flushing Toilet Noise in a Downstairs Bedroom," Journal of Temporal Design in Architecture and the Environment, Vol. 2, pp. 13-19.

7. Sato, S., Ando, Y. (2002). "Apparent Source width (ASW) of Complex Noises in Relation to the Interaural Cross-correlation Function," Journal of Temporal Design in Architecture and the Environment, Vol. 2, pp. 29-32.

8. Shimokura, R., Soeta, Y. (2011). "Characteristics of Train Noise in Ground and Underground Stations with Side and Island Platforms," Journal of Sound and Vibration, Vol. 330, pp. 1621-1633.

9. Soeta, Y., Shimokura, R. (2011). "The Impact of External Environments on Noise Inside a Train Car," Noise Control Engineering Journal, Vol. 59, pp. 581-590.

10. Soeta, Y., Shimokura, R. (2012). "The Impact of External Environments and Wheel-rail Friction on Noise Inside a Train Car," Noise and Vibration Worldwide, Vol. 43, pp. 922.

11. Soeta, Y., Shimokura, R. (2013). "Survey of Interior Noise Characteristics in Various Types of Trains," Applied Acoustics, Vol. 74, pp. 1160-1166.

12. Yost, W. A. (1996). "Pitch Strength of Iterated Ripple Noise," Journal of the Acoustical Society of America, Vol. 100, pp. 3329-3335. 